\title{
Quasi-Static and Tensile Behaviors of the Bamboos
}

\author{
Baoming Gong ${ }^{1}$, Shaohua Cui ${ }^{1}$, Ziye Fan ${ }^{2,3,4}$, Fuguang Ren ${ }^{3}$, \\ Qian Ding ${ }^{2,3,4}$, Yongtao Sun ${ }^{2,3,4,5,{ }^{*}}$, Bin Wang $^{2,3,4}$ \\ 1 School of Materials Science and Engineering, Tianjin University, Tianjin 300350, China \\ 2 Department of Mechanics, Tianjin University, Tianjin 300350, China \\ 3 Tianjin Key Laboratory of Nonlinear Dynamics and Control, Tianjin University, Tianjin \\ 300350, China \\ 4 National Demonstration Center for Experimental Mechanics Education, Tianjin University, \\ Tianjin 300350, China \\ 5 State Key Laboratory for Strength and Vibration of Mechanical Structures, Xi'an Jiaotong \\ University, Xi'an 710049, China \\ * Corresponding Author: ytsun@tju.edu.cn
}

\begin{abstract}
In this paper, quasi-static axial compression tests are performed on the nodal Moso bamboos to study the size effect on energy absorption of the bamboos and the damage pattern of the multiple bamboo columns. Experimental results show that under the same moisture content, growth age and growing environment, the specific energy absorption (SEA) of the test samples increases with the increase of the out-diameter and thickness of the bamboo columns, indicating that size effect exists for energy absorption of the Moso Bamboos. For the multiple bamboo columns, there are mainly three failure modes for the constituent single bamboo columns: splitting above the node, splitting below the node and splitting through the node. Also, the tensile tests are conducted on three kinds of dog-bone shaped bamboo samples to investigate the macroscopic tensile fracture mode in the longitudinal direction of Moso bamboos. Results show that there is no direct relationship between the fracture pattern and moisture content of the bamboos, as well as the growth age of the bamboos. However, the tensile loading rate and the shape of the dog-bone shaped bamboo sample could affect the macroscopic fracture pattern of the bamboos in some cases.
\end{abstract}

Keywords: moso bamboo; quasi-static behavior; tensile behavior; size effect on energy absorption; damage pattern of the multiple bamboo columns; macroscopic tensile fracture mode

\section{Introduction}

As a common natural material, bamboos have the advantages of fast-growing, sustainability, environmental friendliness, and the capability of being reused or recycled [1-3]. In the past several years they have drawn extensive attention in the research fields. In the aspect of structural materials, they could be used as bamboo scaffolds [4-5], bamboo bridges [6], laminated bamboo [7-11], parallel strand bamboo lumber [12-13], 
bamboo concrete/cement composite structure [14-20], bamboo fiber reinforced composites [21-26], sound absorbing materials [27] and so on. In the aspect of mechanical properties, researches revealed that bamboos have excellent flexibility and fracture toughness, which are mainly related to their tubular shape [28- 32], the selfadaptive distribution of nodes [24, 33-34], the gradient distribution of vascular bundles and the hierarchical fiber/foam-like parenchyma cells [35-43].

With respect to energy absorption of the bamboos, Zou et al. [44] carried out the drop-weight and dynamic tensile tests on bamboo species Phyllostachys pubescens. They showed that bamboo is a tubular structure with excellent mechanical and energy absorption properties. To be specific, the energy absorption of nodal samples is greater than that of the internode samples and the specific energy absorption (SEA) of nodal samples could be close to that of aluminium alloy and steel tube, and the SEA of the internode samples could be close to that of copper tube. At the same time, inspired by bamboos, using the bionic method they proposed a new type of thin-walled structures with excellent energy absorption under lateral/axial impact [45].

With respect to tensile fracture properties of the bamboos, usually the tensile tests are carried out on dog-bone shaped bamboo samples. Shao et al. [46] performed tensile tests on the macroscopic bamboo blocks (4 years old) and the mesoscopic bamboo fiber and showed that the tensile strength of bamboo fiber obtained from the tests on bamboo blocks was higher than that on separated fiber bundles. Habibi and Lu [47] studied crack growth mode in the hierarchical cellular structure of the 5 years old mature Moso bamboo and revealed that fibers' pull out was one of the prominent feature in tensile fracture surface. Chen et al. [48] studied tensile properties of bamboo in different sizes and revealed that compared with single bamboo fibers and bamboo fiber bundles, the tensile strength of bamboo strips was reduced by $67.7 \%$ and $3.3 \%$, respectively. By means of digital speckle correlation method (DSCM) and microscopic techniques, Liu et al. [49] studied tensile behaviour and fracture mechanism of the 4 years old moso bamboo (Phyllostachys pubescens). In their experiments, hybrid I-II failure mode was observed, i.e., crack opening (in tensile stress) and shear sliding (in shear stress). Jakovljevic et al. [50] studied the influence of humidity on mechanical properties of bamboo for bicycles and showed that the tensile, compressive and bending strength of bamboo significantly decreased after bamboo samples were kept in an environment with humidity level of $60 \%$.

In general, mechanical properties and engineered structural applications of bamboos have been extensively studied in the existing literature. However, to the best of the authors' knowledge, size effect on energy absorption of the bamboos, i.e., under the same moisture content, growth age and growing environment, how will the size of 
thickness and out-diameter influence SEA of the bamboos, has not been studied so far. Therefore, in this paper, choosing Moso Bamboos as the research object, axial quasistatic compression tests are performed on 4 groups of nodal bamboo columns. Damage process and the effect of size on energy absorption of the bamboos are investigated.

Also, damage pattern of the multiple bamboo columns and the tensile fracture modes of different Moso bamboos are still not fully studied. Therefore, this paper also intends to give more details on damage pattern of the multiple bamboo columns and macroscopic tensile fracture mode in the longitudinal direction of Moso bamboos. About damage pattern of the multiple bamboo columns, quasi-static axial compression tests are performed on three groups of nodal bamboo samples. About macroscopic tensile fracture mode in the longitudinal direction of Moso bamboos, tensile tests are conducted on three kinds of dog-bone shaped samples processed from longitudinal sections of different Moso bamboos. The effects of growth age, moisture content, tensile loading rate and the shape of the dog-boned shaped bamboo samples are analyzed.

The results in this paper are expected to be inspirational for the bionic crashworthiness optimization design of thin-walled tube structures and to be useful to understand the mechanical properties of the bamboos more systematically and comprehensively.

\section{Size effect on energy absorption of the bamboos under axial quasi-static compressions}

In this part, size effect on energy absorption of the bamboos under axial quasistatic compressions is analyzed.

\subsection{Materials}

The test samples are nodal bamboo columns (Figure 1) as those studied in Ref. [44]. Their lengths are $16 \mathrm{~cm} \pm 0.1 \mathrm{~cm}$. The nodes locate around the middle positions of the bamboo columns. And cross sections of the two ends are perpendicular to the axis of bamboo columns. The number of the test samples is 12 . They are divided into 4 groups (Figure 1). Each group has 3 bamboo columns cutting from the middle part of the same bamboo. To examine size effect on energy absorption of bamboos, the 4 groups of test samples are cut from 4 bamboos of the species Moso Bamboo with the same growth age (4 years) and moisture content (around 20\%) but different diameters. Besides, the 4 bamboos are produced at the same field of Fujian Province, China. Thus, the influence of growing environment or climate on material properties of the test samples can be ignored. The detailed geometrical parameters of the 4 groups test samples are shown in Table 1. The outer diameter, thickness and mass of the test 
samples on the same group are similar. The average thickness and the average mass for each group are increasing from Group 1 to Group 4.

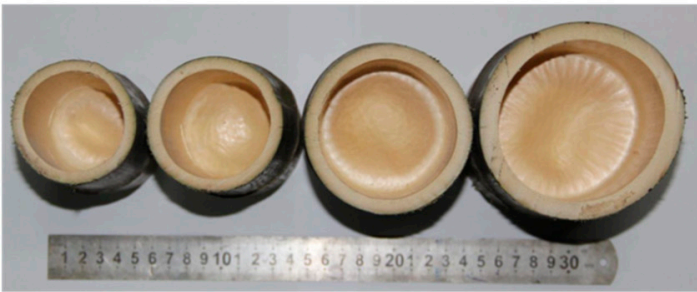

(a)

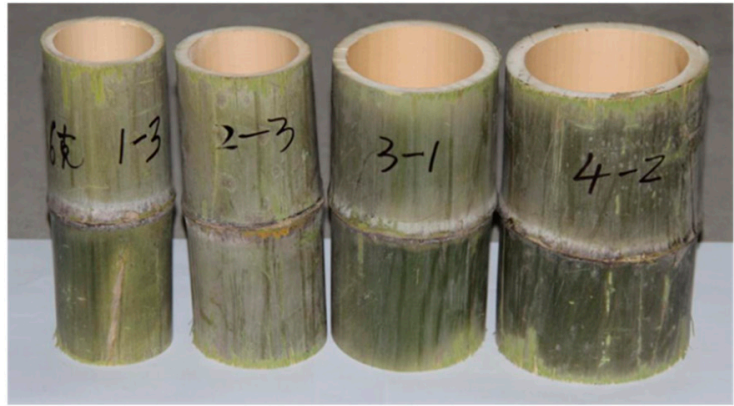

(b)

Figure 1. (a) Top view and (b) front view of the test samples

Table 1. Geometrical parameters of the 4 groups of bamboo columns

\begin{tabular}{|c|c|c|c|c|c|c|c|c|c|c|c|c|}
\hline \multirow{2}{*}{$\begin{array}{c}\text { Samples } \\
\text { Number }\end{array}$} & \multicolumn{3}{|c|}{ Group 1} & \multicolumn{3}{|c|}{ Group 2} & \multicolumn{3}{|c|}{ Group 3} & \multicolumn{3}{|c|}{ Group 4} \\
\hline & $1-1$ & $1-2$ & $1-3$ & $2-1$ & $2-2$ & $2-3$ & $3-1$ & $3-2$ & $3-3$ & $4-1$ & $4-2$ & $4-3$ \\
\hline $\begin{array}{l}\text { Outer diameter } \\
\qquad(\mathrm{mm})\end{array}$ & 52.2 & 60.42 & 60.34 & 70.32 & 70.42 & 69.8 & 83.54 & 82.54 & 80.72 & 101.88 & 101.84 & 101.36 \\
\hline Thickness (mm) & 5.55 & 5.59 & 5.58 & 6.84 & 6.26 & 6.7 & 7.36 & 6.84 & 7.34 & 10.92 & 9.64 & 9.52 \\
\hline Mass (g) & 157.1 & 167.4 & 180.6 & 233.9 & 210.1 & 220.5 & 253.6 & 277.5 & 289.7 & 497.3 & 442.3 & 470.1 \\
\hline $\begin{array}{c}\text { Average } \\
\text { thickness }(\mathrm{mm})\end{array}$ & & 5.57 & & & 6.60 & & & 7.18 & & & 10.03 & \\
\hline $\begin{array}{l}\text { Average } \\
\text { mass (g) }\end{array}$ & & 168.3 & & & 221.5 & & & 270.6 & & & 469.9 & \\
\hline
\end{tabular}

\subsection{Axial quasi-static compression tests}

Axial quasi-static compression tests are performed on the Electro-hydraulic

Servo Universal Testing Machine at Tianjin University. The loading process is displacement controlled and the rate is $5 \mathrm{~mm} / \mathrm{min}$. The test samples are fixed on the test machine as shown in Figure 2.

The specific energy absorption (SEA), i.e., the energy absorbed per unit mass of the bamboo columns, is used to evaluate the energy absorption capabilities of the bamboo samples [44]. The expression of SEA is

$$
S E A=\frac{E_{\text {total }}}{M}
$$

where $E_{\text {total }}$ is the total energy absorbed by the sample and equals to the area below the loading displacement-force curve, $M$ is the mass of the test sample. 


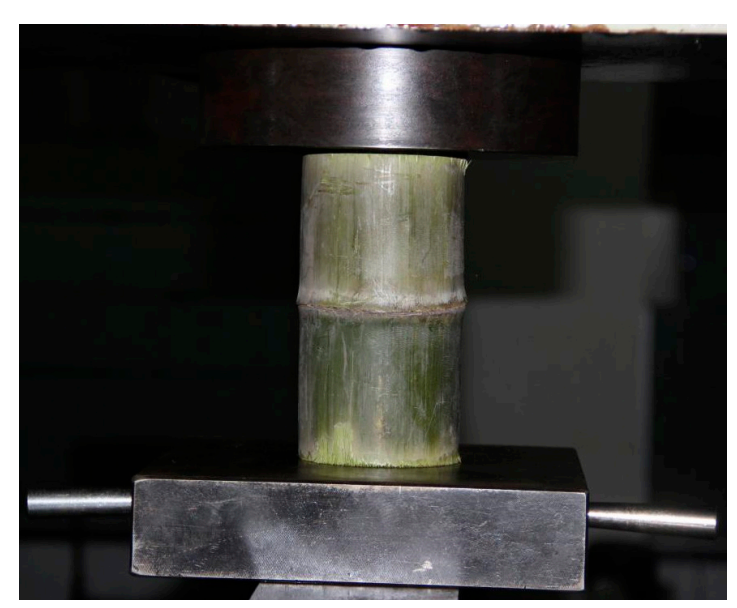

Figure 2. Schematic of the axial quasi-static compression test

\subsection{Results and discussions}

\subsubsection{Destruction process of the test samples}

Under quasi-static axial compression, destruction process of the test sample No. 4-3 is shown in Figure 3. And the corresponding quasi-static displacement-force curve for No. 4-3 is given in Figure 4. Generally the destruction process of the test nodal bamboo samples is similar to that of sample No. 4-3 and can be described as following: At first, the loading process is elastic (Figures $3 \mathrm{a}$ and $3 \mathrm{~b}$ ). With the increase of the loading displacement, cracks occur in the node position due to buckling of the bamboo column. That is to say, the bamboo column is split into a group of bamboo slices with uneven widths, as shown in Figure 3c. Then, with the continuing increase of the loading displacement, the bamboo slices are split into more smaller ones (Figure 3d). After that, peeling fractures gradually occur from the surface of the bamboo slices because of the continuing buckling of the bamboo slices (Figure 3e). Finally, the bamboo column fails rapidly due to buckling failure of the bamboo slices. 


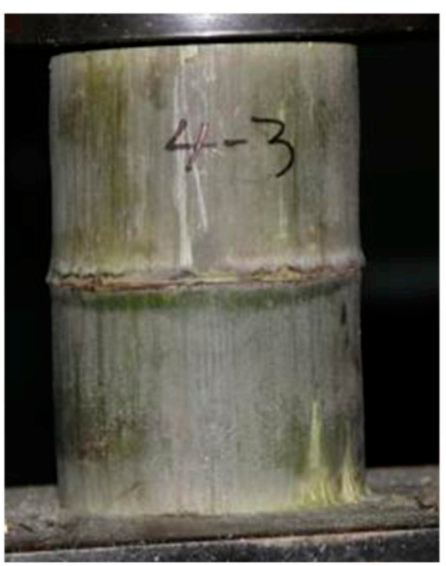

(a)

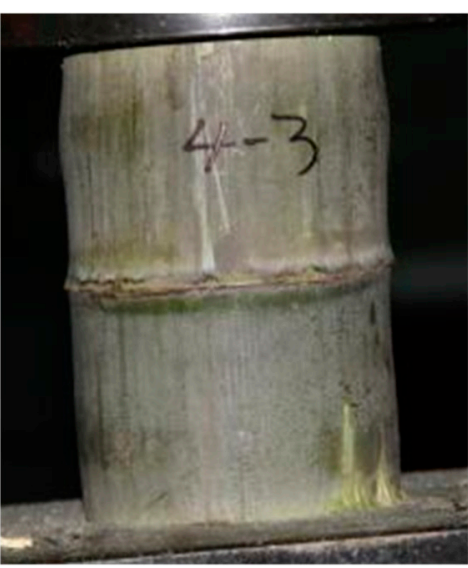

(b)

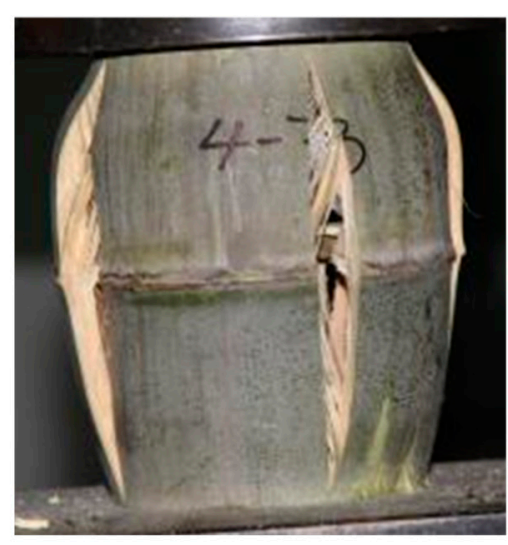

(c)

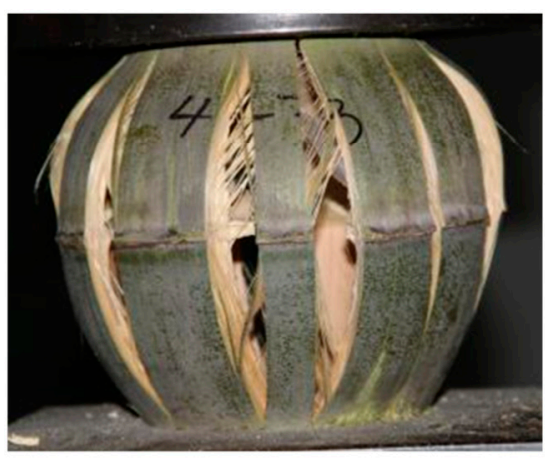

(d)

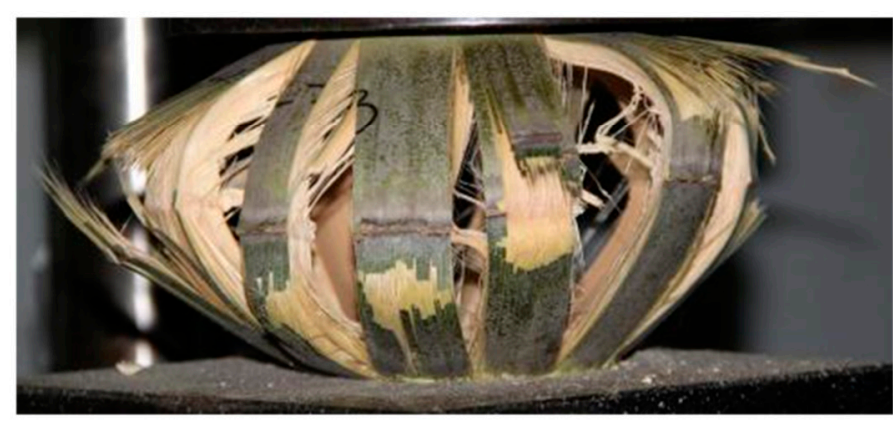

(e)

Figure 3. Destruction process of the test sample No. 4-3

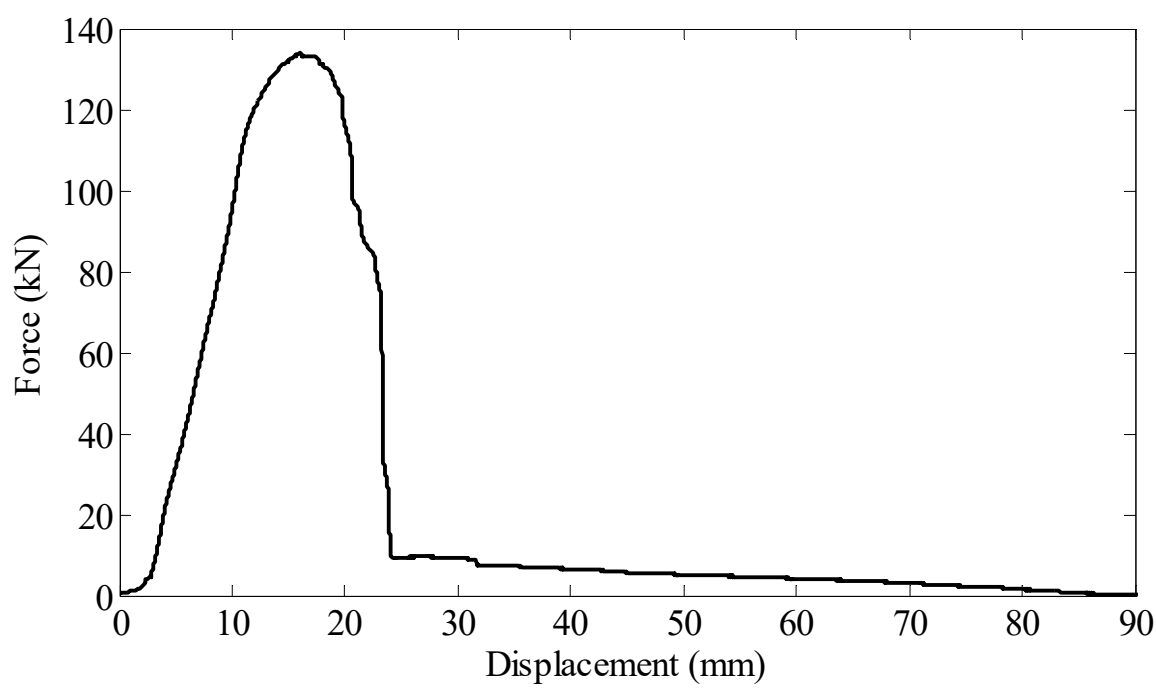

Figure 4. The loading displacement-force curve of the test sample No. 4-3

\subsubsection{Energy absorptions of the test samples}

Energy absorption properties of the 4 groups of test bamboo samples under quasistatic axial compression are given in Table 2. From Table 2, one can see that the energy absorption, SEA and the peak crushing force of the test samples on the same group are 
similar overall and generally they are increasing from Group 1 to Group 4. The average energy absorptions of the 4 groups of test samples are 375.69, 719.67, 935.33 and $2130.49 \mathrm{~J}$, respectively. And the average SEA of the 4 groups of test samples are 2.23, $3.25,3.42$ and $4.53 \mathrm{~kJ} / \mathrm{kg}$, respectively. Combining Tables 1 and 2, we conclude that energy absorption capabilities increase with the increase of the size of bamboos. That is to say, size effect exists for energy absorption of the Moso Bamboos studied in this paper. The reason is that the bigger the size is, the stronger the influence of nodes and the gradient distribution of vascular bundles in the microstructure of bamboos will be, thus, the stronger the energy absorption abilities of the bamboos will be.

Table 2. Energy absorption properties of the 4 groups of test bamboo samples

\begin{tabular}{|c|c|c|c|c|c|c|c|c|c|c|c|c|}
\hline \multirow{2}{*}{$\begin{array}{l}\text { Samples } \\
\text { Number }\end{array}$} & \multicolumn{3}{|c|}{ Group 1} & \multicolumn{3}{|c|}{ Group 2} & \multicolumn{3}{|c|}{ Group 3} & \multicolumn{3}{|c|}{ Group 4} \\
\hline & $1-1$ & $1-2$ & $1-3$ & $2-1$ & $2-2$ & $2-3$ & $3-1$ & $3-2$ & $3-3$ & $4-1$ & $4-2$ & $4-3$ \\
\hline $\begin{array}{c}\text { Energy } \\
\text { Absorption(J) }\end{array}$ & 348 & 403 & 376 & 789 & 755 & 614 & 871 & 1052 & 883 & 2151 & 2007 & 2233 \\
\hline SEA $(\mathrm{kJ} / \mathrm{kg})$ & 2.21 & 2.41 & 2.08 & 3.37 & 3.60 & 2.79 & 3.43 & 3.79 & 3.05 & 4.33 & 4.54 & 4.75 \\
\hline $\begin{array}{c}\text { Peak crushing } \\
\text { force }(\mathrm{kN})\end{array}$ & 50.4 & 54.1 & 60.7 & 74.6 & 76.9 & 70.7 & 91.8 & 91.5 & 90.7 & 140 & 131 & 134 \\
\hline Average & & & & & & & & & & & & \\
\hline Energy & \multicolumn{3}{|c|}{375.69} & \multicolumn{3}{|c|}{719.67} & \multicolumn{3}{|c|}{935.33} & \multicolumn{3}{|c|}{2130.49} \\
\hline \multicolumn{13}{|l|}{ Absorption(J) } \\
\hline $\begin{array}{c}\text { Average } \\
\text { SEA }(k J / k g)\end{array}$ & \multicolumn{3}{|c|}{2.23} & \multicolumn{3}{|c|}{3.25} & \multicolumn{3}{|c|}{3.42} & \multicolumn{3}{|c|}{4.53} \\
\hline
\end{tabular}

\subsection{Conclusion}

Size effect on energy absorptions of the nodal Moso Bamboo columns are analyzed in this part through the quasi-static axial compression tests. Results show that under the same moisture content, growth age and growing environment, SEA increases with the increase of the out-diameter and thickness of the test bamboo samples. That is to say, size effect exists for energy absorption of the Moso Bamboos studied in this paper.

\section{Damage pattern of the multiple bamboo columns under axial quasi-static compressions}

In this part, damage patterns of the multiple bamboo columns (Figure 5) under axial quasi-static compressions are observed.

Like those in part 1, the test samples used in this part are also nodal bamboo columns with the lengths $16 \mathrm{~cm} \pm 0.1 \mathrm{~cm}$. The nodes locate around the middle positions of the bamboo columns and cross sections of the two ends are perpendicular to the axis 
of bamboo columns. They are also cut from bamboos of the species Moso Bamboo with similar growth age (4 years old), moisture content and produced at the same field of Fujian Province, China. The outer diameter and thickness of the samples are around 45 $\mathrm{mm}$ and $4 \mathrm{~mm}$, respectively.

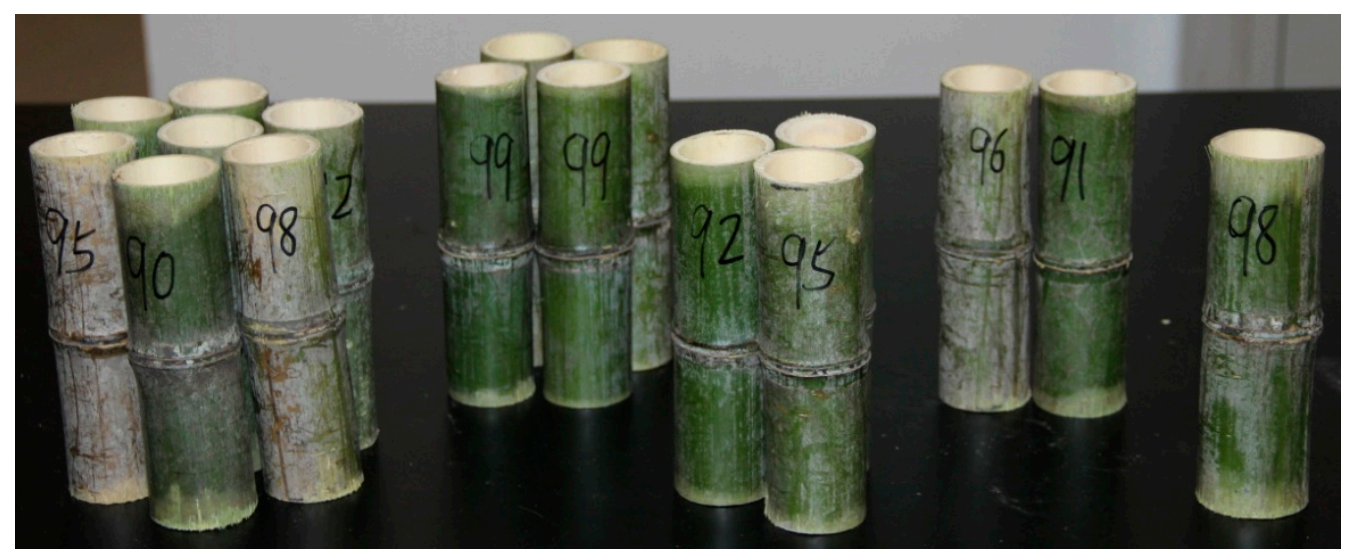

(a)

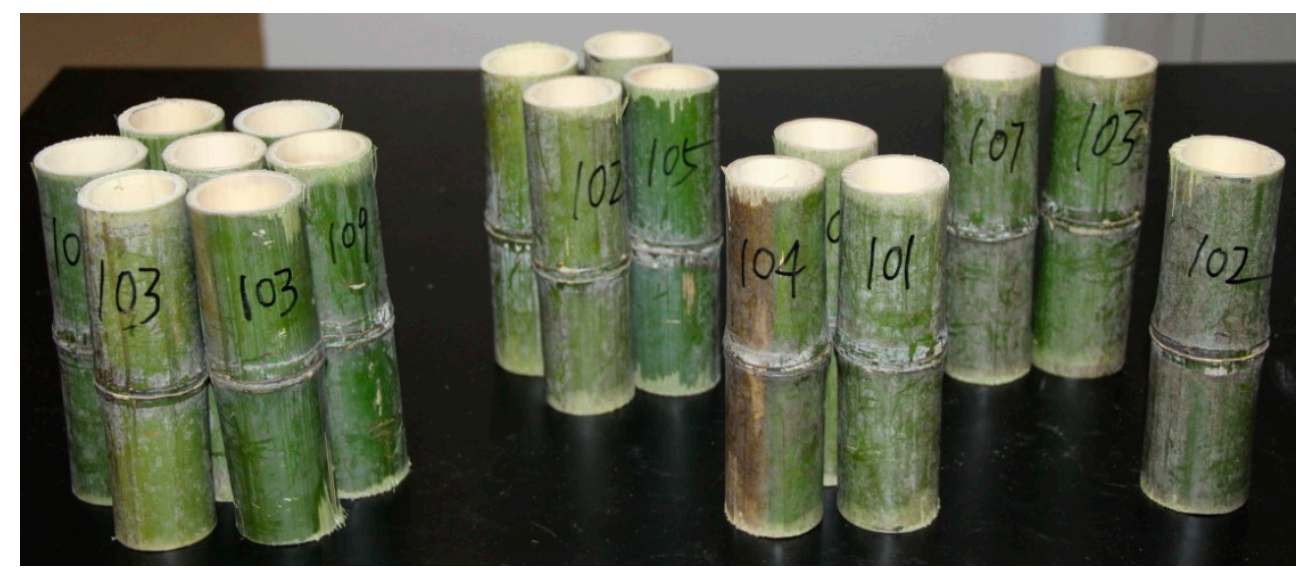

(b)

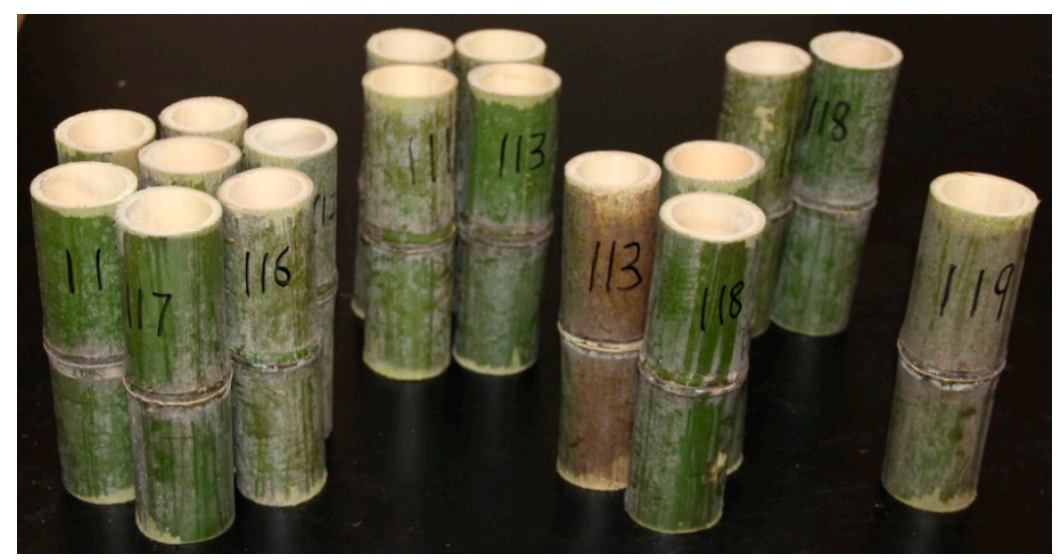

(c)

Figure 5. The multiple bamboo columns: (a) Group I (90-99g); (b) Group II (100-109g); (c) Group III (110-119g)

As shown in Figure 5, three groups of nodal samples, whose masses are in the range 90-99g (Group I), 100-109g (Group II) and 110-119g (Group III) respectively, 
are analyzed. Each group contains 5 groups of bamboo columns, for which the number of bamboo columns are 1, 2, 3, 5 and 7, respectively (Figure 5). The 15 samples are compressed on the Electro-hydraulic Servo Universal Testing Machine through the displacement control. The loading rate is $5 \mathrm{~mm} / \mathrm{min}$. For the multiple bamboo columns, the columns are freely and compactly put together. And they are fixed on the two ends due to the compression of the testing machine. Failure modes of the three groups of test samples are shown in Figures. 6-8, respectively.

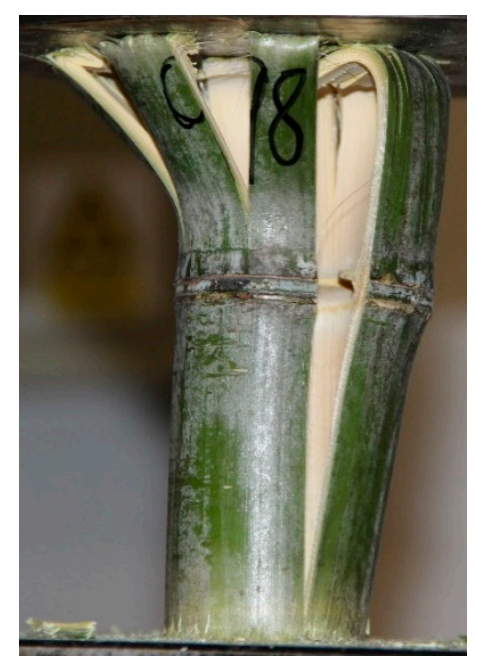

(a)

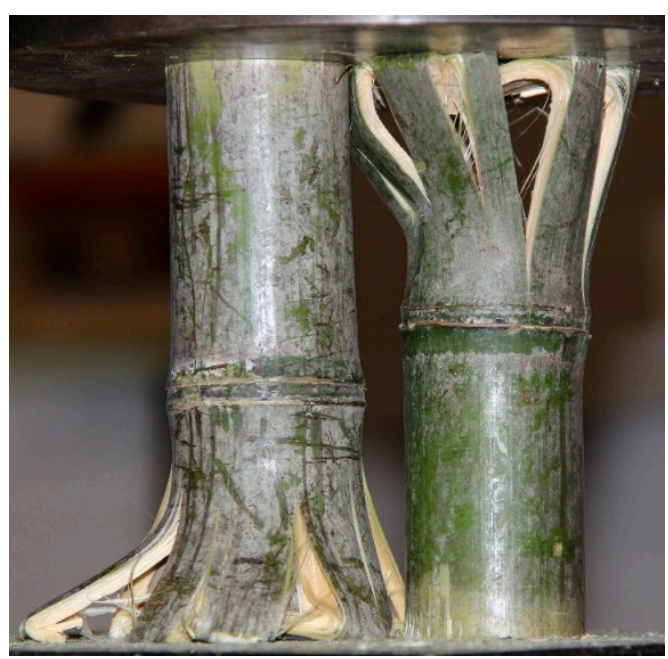

(b)

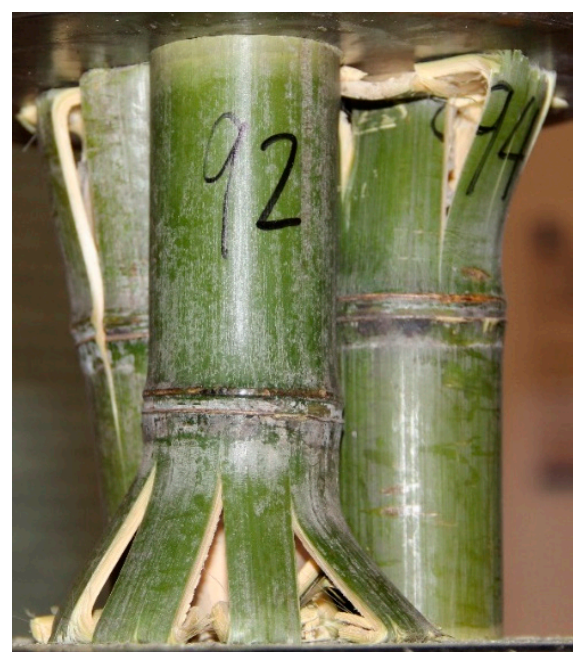

(c) 


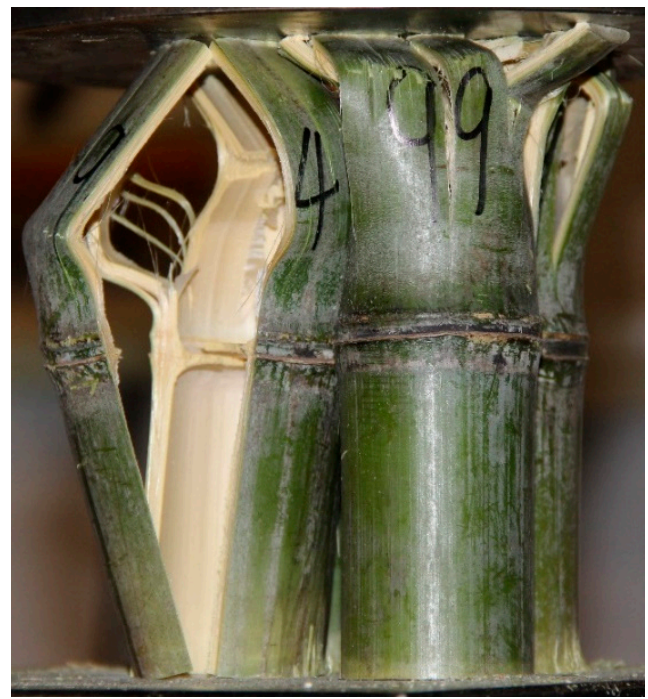

$(\mathrm{d} 1)$

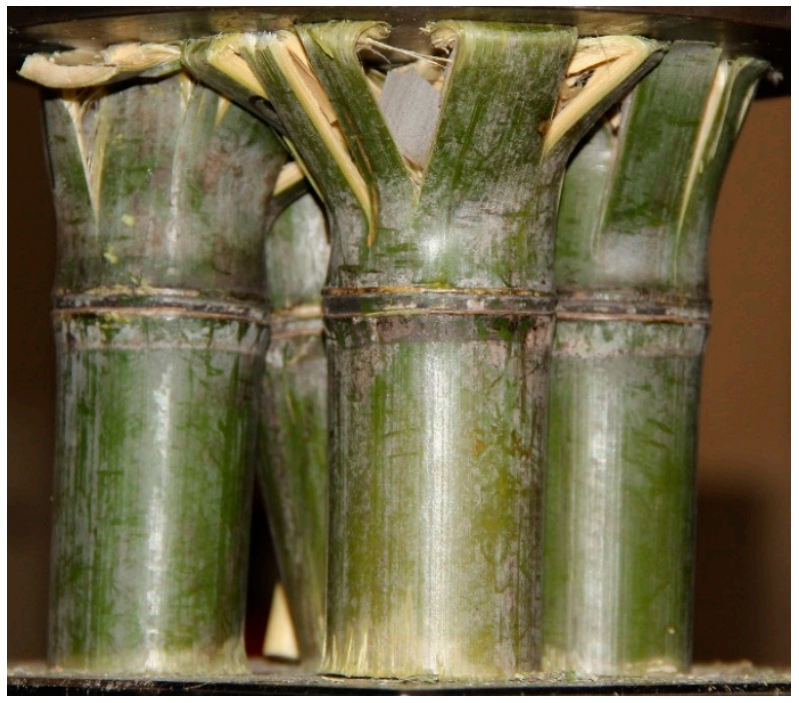

$(d 2)$

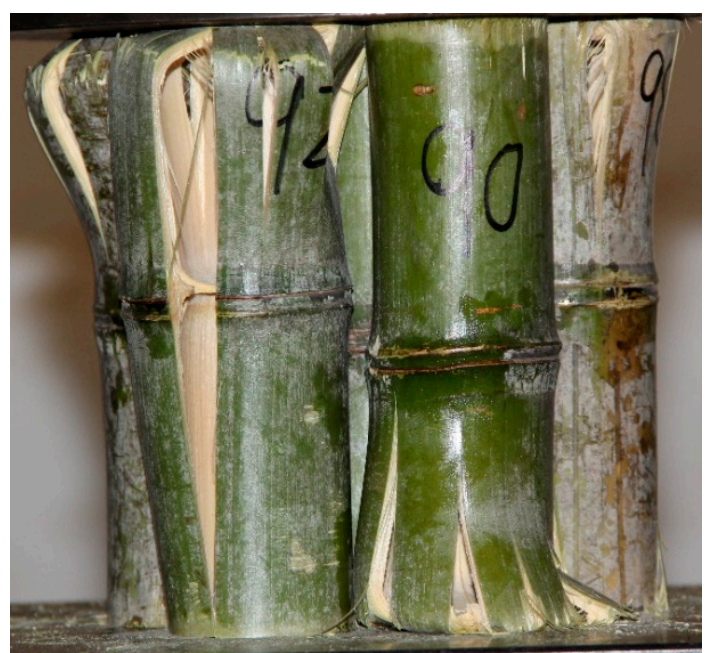

(e1)

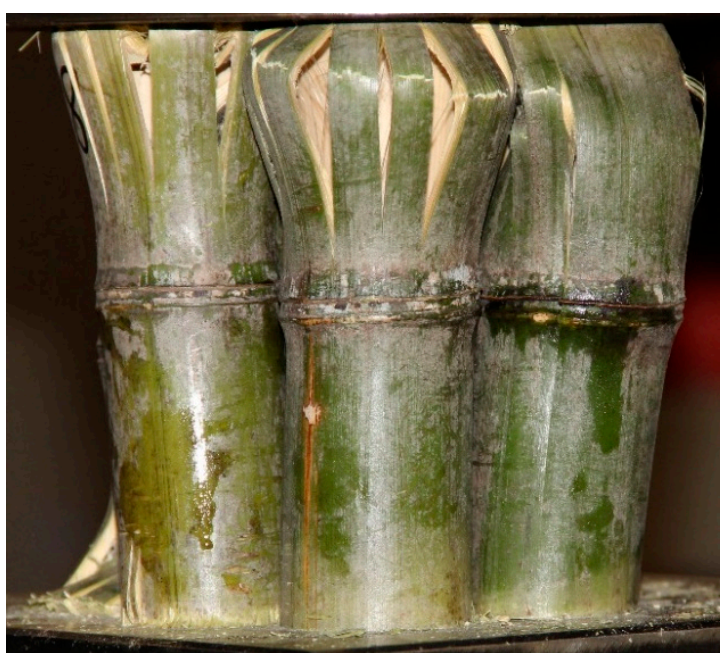

(e2)

Figure 6. Failure modes of the Group I multiple bamboo columns shown in Figure 5a under axial quasi-static compressions: (a) 1 bamboo column; (b) 2 bamboo columns; (c) 3 bamboo columns; (d1) front view of the 5 bamboo columns; (d2) back view of the 5 bamboo columns; (e1) front view of the 7 bamboo columns; (e2) back view of the 7 bamboo columns. 


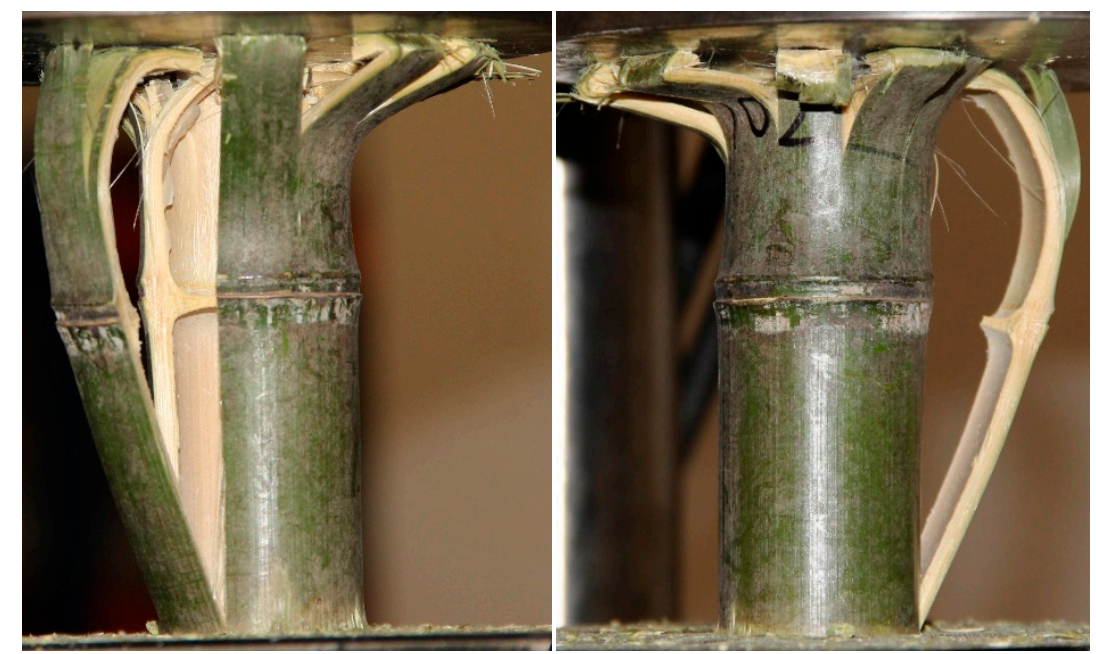

(a1)

(a2)

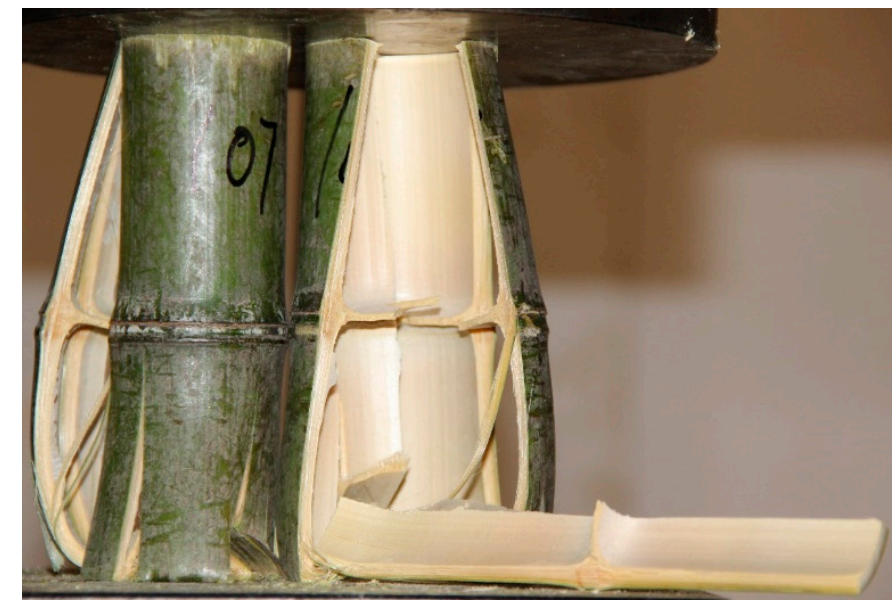

(b1)

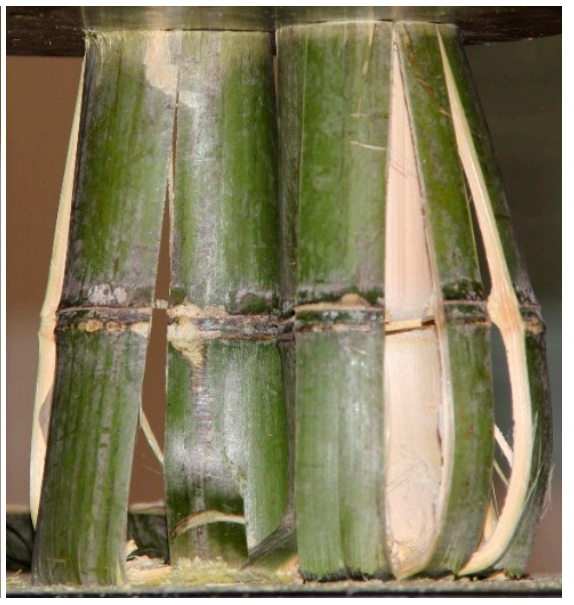

(b2)

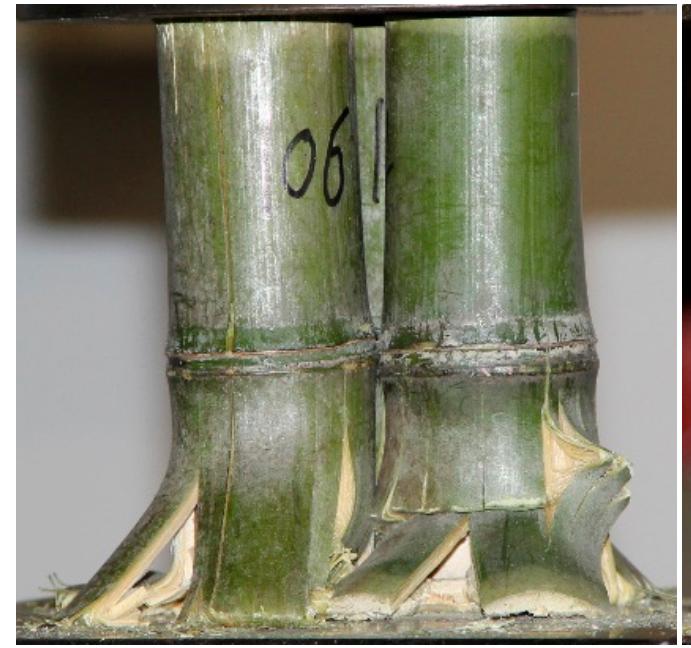

(c1)

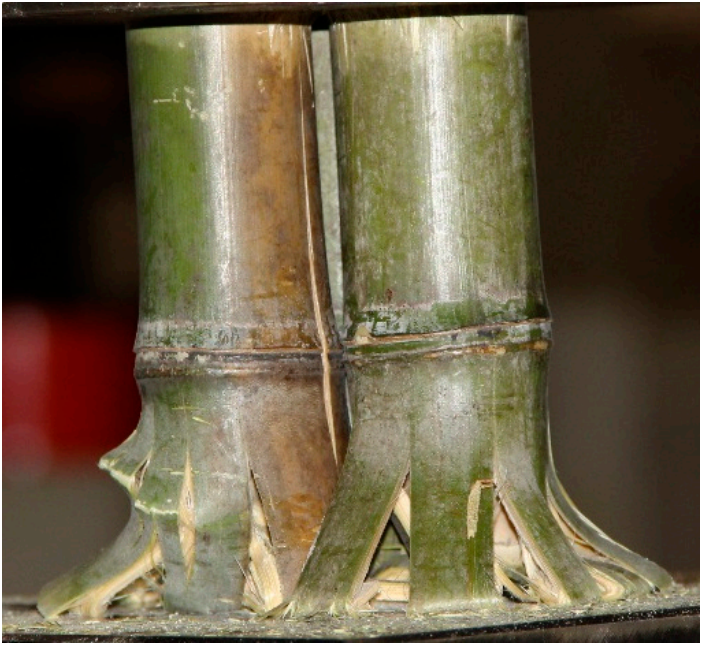

(c2) 


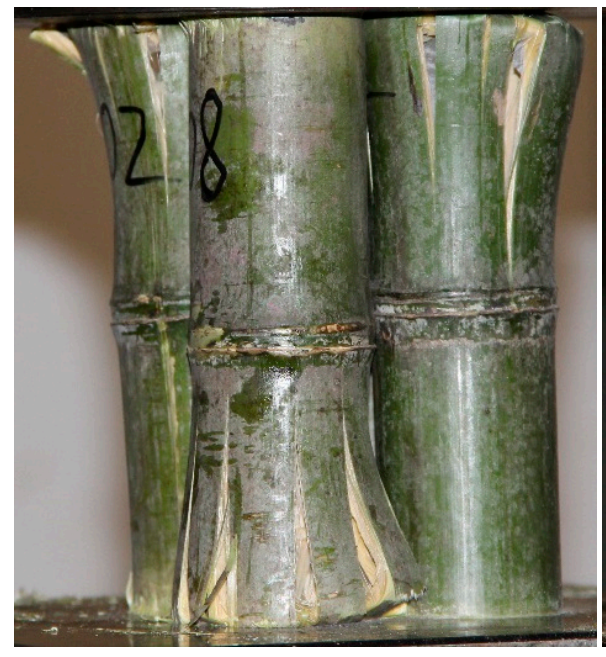

$(\mathrm{d} 1)$

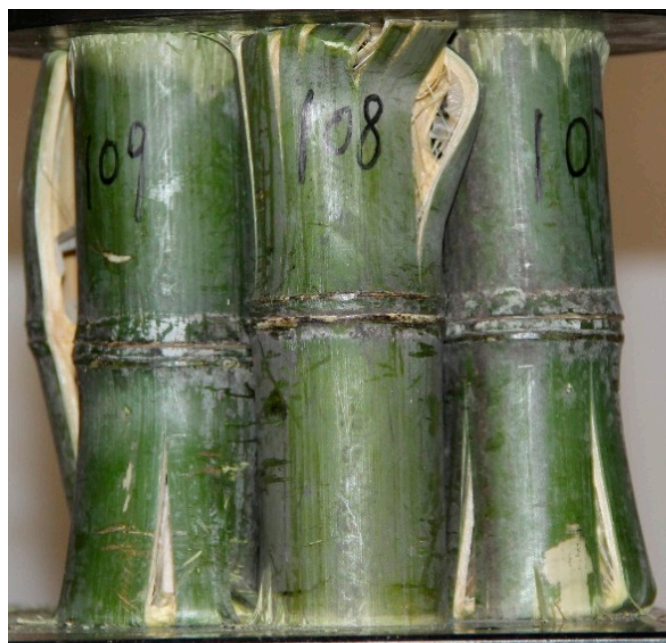

(e1)

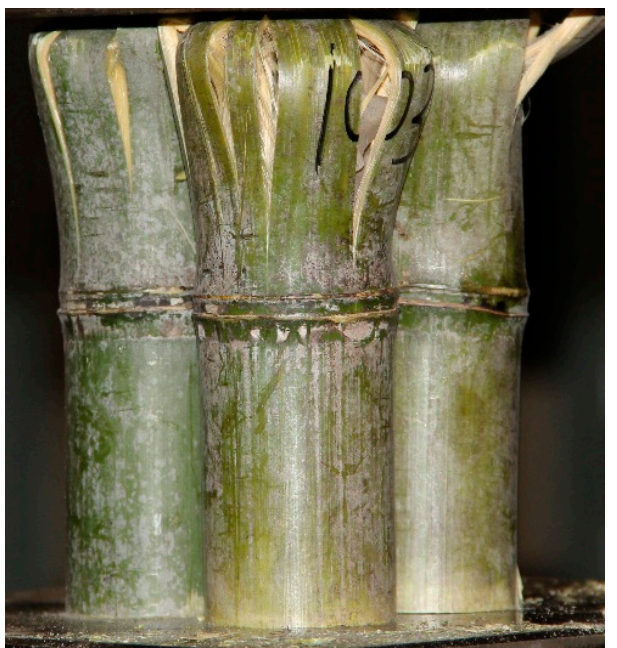

$(\mathrm{d} 2)$

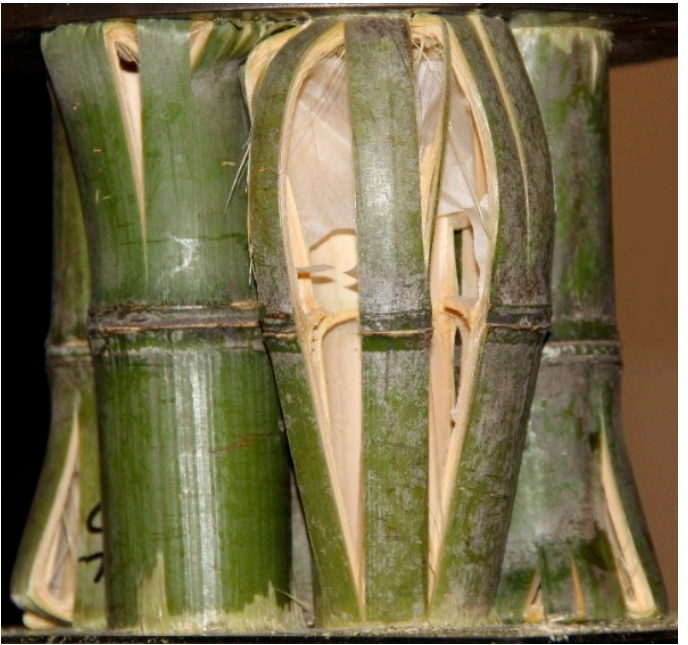

(e2)

Figure 7. Failure modes of the Group II multiple bamboo columns shown in Figure 5b under axial quasi-static compressions: (a1) front view of the 1 bamboo column; (a2) back view of the 1 bamboo column; (b1) front view of the 2 bamboo columns; (b2) back view of the 2 bamboo columns; (c1) front view of the 3 bamboo columns; (c2) back view of the 3 bamboo columns; (d1) front view of the 5 bamboo columns; (d2) back view of the 5 bamboo columns; (e1) front view of the 7 bamboo columns; (e2) back view of the 7 bamboo columns. 


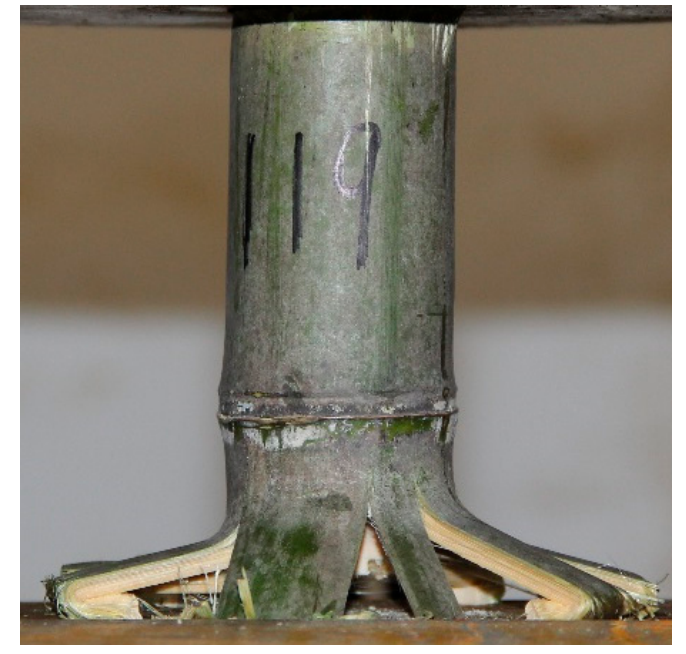

(a)

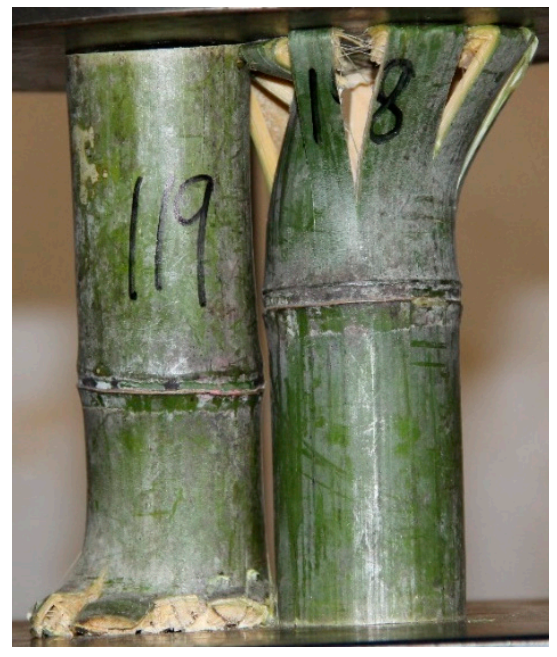

(b)

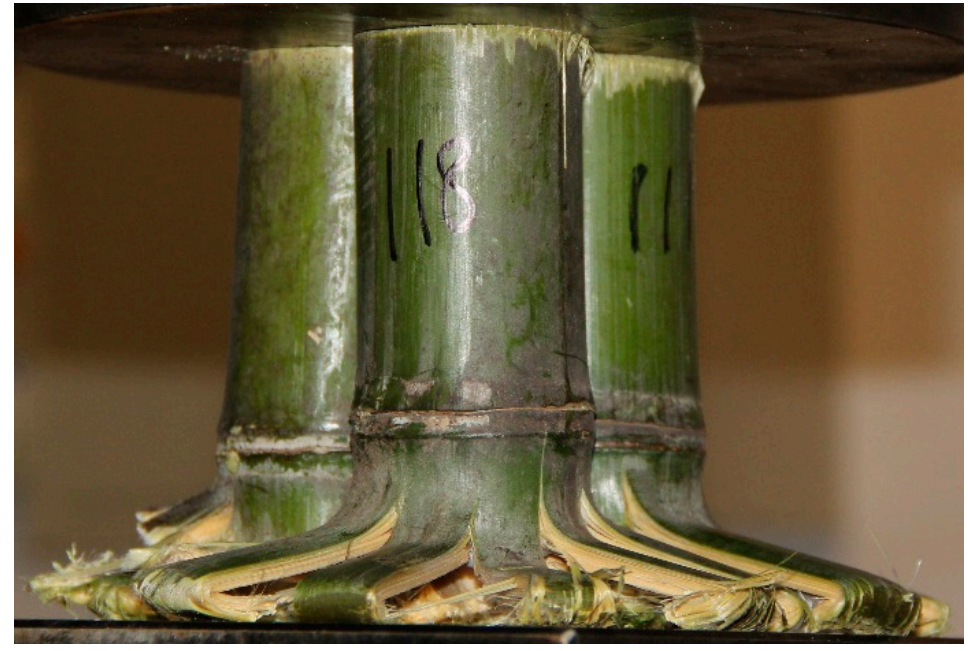

(c)

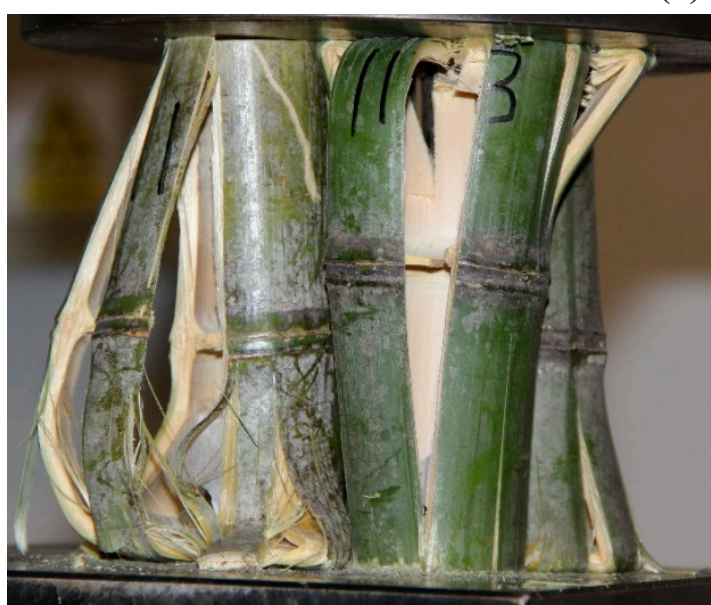

(d1)

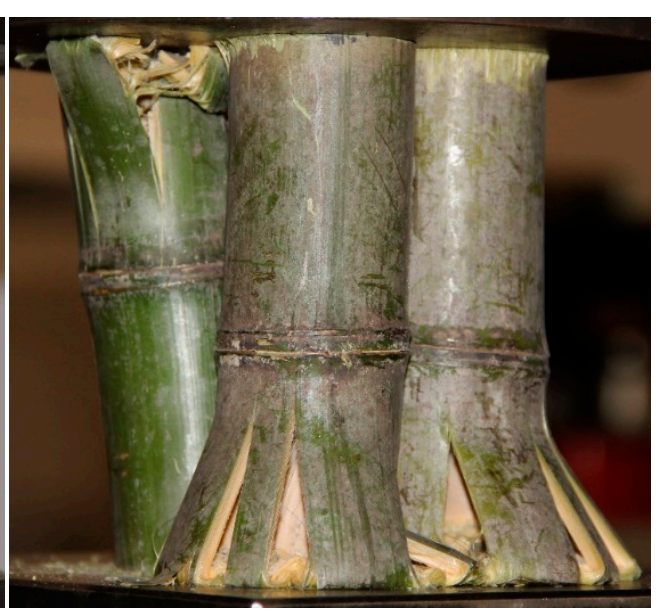

(d2) 


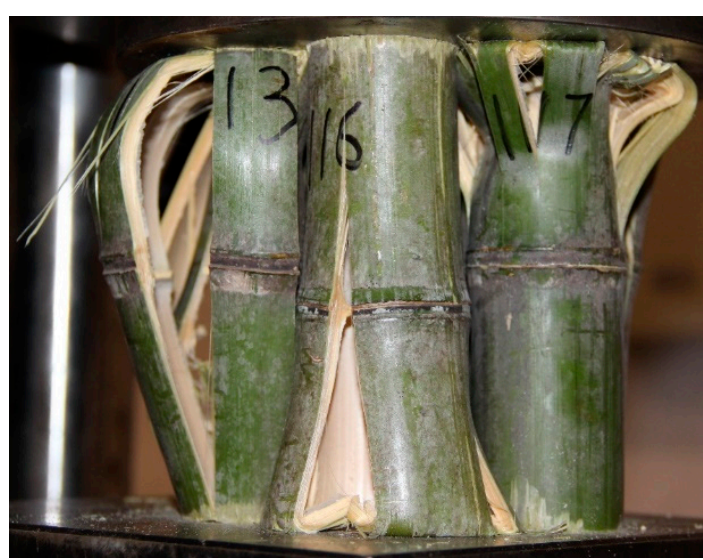

(e1)

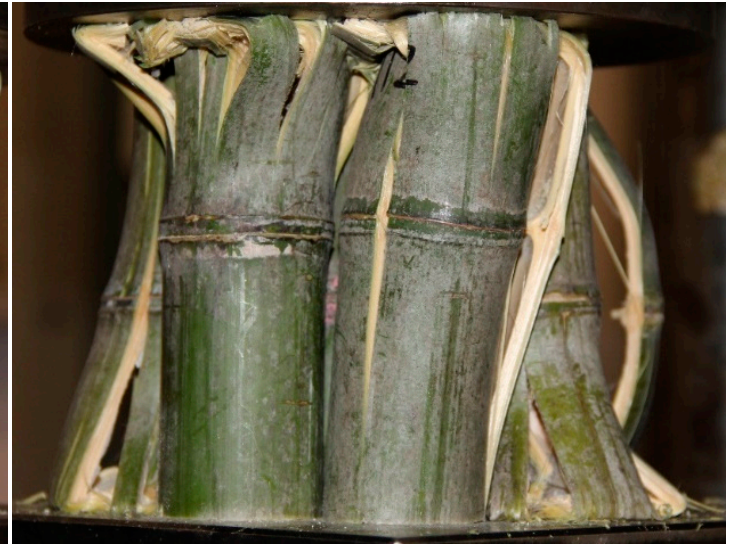

(e2)

Figure 8. Failure modes of the Group III multiple bamboo columns shown in Figure $5 \mathrm{c}$ under axial quasi-static compressions: (a) 1 bamboo column; (b) 2 bamboo columns; (c) 3 bamboo columns; (d1) front view of the 5 bamboo columns; (d2) back view of the 5 bamboo columns; (e1) front view of the 7 bamboo columns; (e2) back view of the 7 bamboo columns.

From Figures 6-8 we can see that for the Moso bamboos studied in this part there are mainly three failure modes for each bamboo column: splitting above the node, splitting below the node and splitting through the node. For the multiple bamboo columns, the failure mode is the combination of one (Figures $7 \mathrm{~b}, 7 \mathrm{c}$ and $8 \mathrm{c}$ ), two (Figures $6 \mathrm{~b}, 7 \mathrm{~d}, 8 \mathrm{~b}$ etc.) or three (Figures $6 \mathrm{e}, 7 \mathrm{e}$ and $8 \mathrm{e}$ ) of the three failure modes. Apparently, with the increase of the number of the bamboo columns, the failure mode becomes more complicated. In addition, in the loading process the bamboo columns squeeze each other which also makes the failure mode more complicated. From the point of view of energy absorption, the preferred failure modes are splitting above the node and splitting below the node, because these two kinds of failure modes allow the bamboo fibers to be sufficiently crushed and thus the nodal samples could absorb more energy [44].

The results in this part may have implications for the bioinspired design of the multiple thin walled structures for engineering application.

\section{Macroscopic tensile behaviors of the bamboos under different loading rates}

In this part, to study the macroscopic tensile fracture mode in the longitudinal direction of Moso bamboos, tensile tests are conducted on three kinds of dog-bone shaped samples processed from longitudinal sections of different Moso bamboos (Figure 9). To assure their properties' similarity, dog-bone shaped samples of the same kind are processed from the same bamboo culm between two adjacent bamboo nodes. The first kind of samples are machined from the 2 years old bamboo and have the fresh moisture content $50 \%$ (Figure 9b). The second kind of samples are machined from the 3 years old bamboo and dehydrated with ethanol (Figure 9c). And the third kind of 
samples are machined from the 5 years old bamboo and soaked in water for more than 24 hours (Figure 9d). The tensile tests are conducted on a MTS810 testing machine.

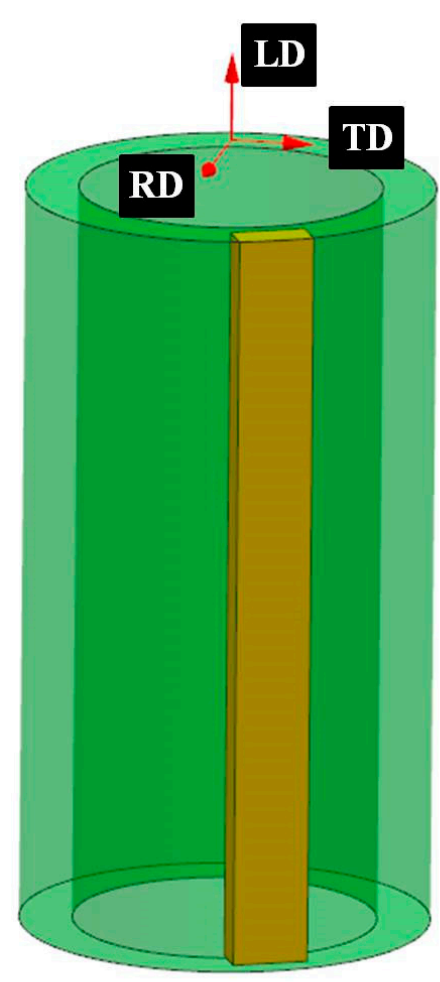

(a)

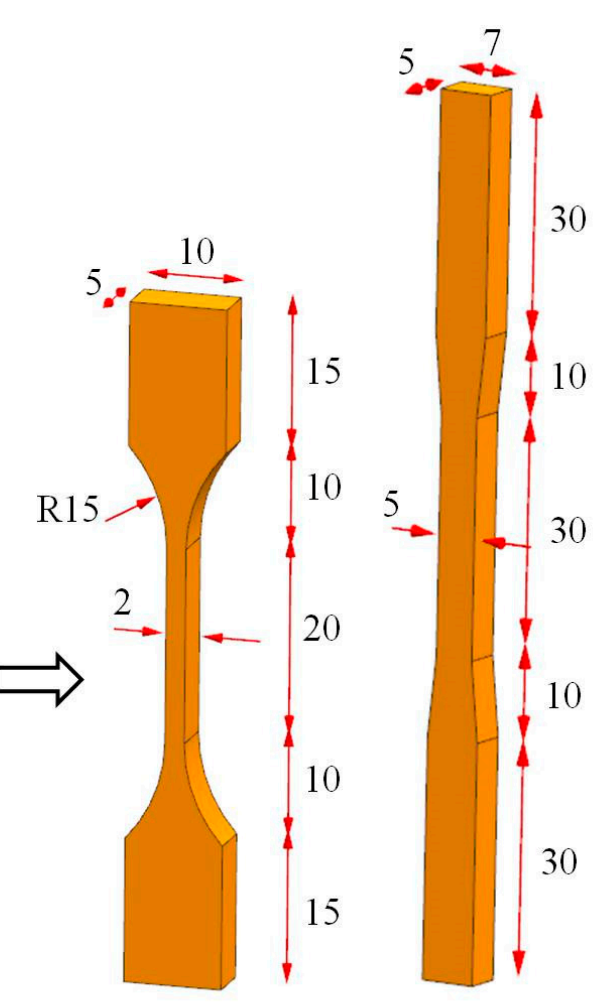

(b) (c)

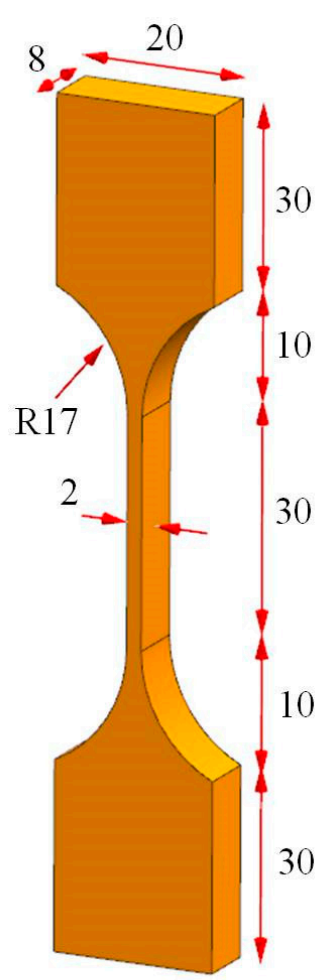

(d)

Figure 9. Three kind of dog-bone shaped bamboo samples: (a) Schematic of the bamboo culm from which the dog-bone shaped samples are machined (LD: longitudinal direction; TD: transversal direction; RD: radial direction); (b) 2 years old Moso bamboo with natural moisture content 50\%; (c) 3 years old Moso bamboo and dehydrated with ethanol; (d) 5 years old Moso bamboo and soaked in water for more than 24 hours.

The first kind of 9 samples, machined from the 2 years old bamboo and with natural moisture 50\%, are divided into 3 groups. Each group contains 3 samples. The tensile loading rates for the three groups are 2, 20 and $200 \mathrm{~mm} / \mathrm{s}$, respectively, as shown in Figure 10. From Figure 10, it is apparent that all the samples are brittle fracture and the phenomenon of fibers' pull out almost does not exist. At the same time, the loading rates have no influence on the tensile fracture mode. 


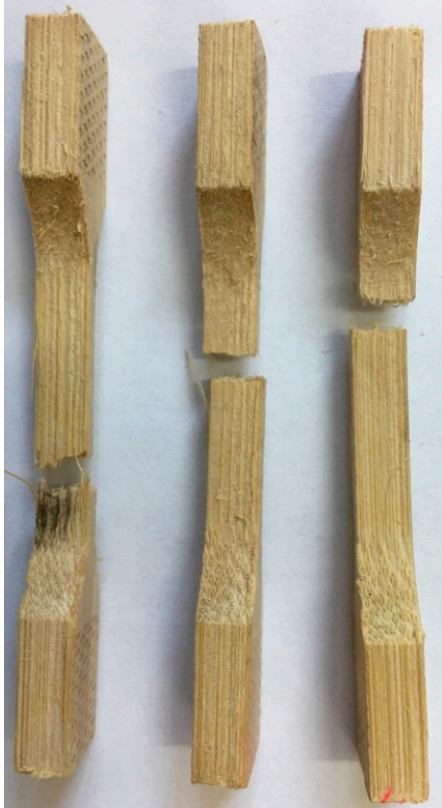

(a)

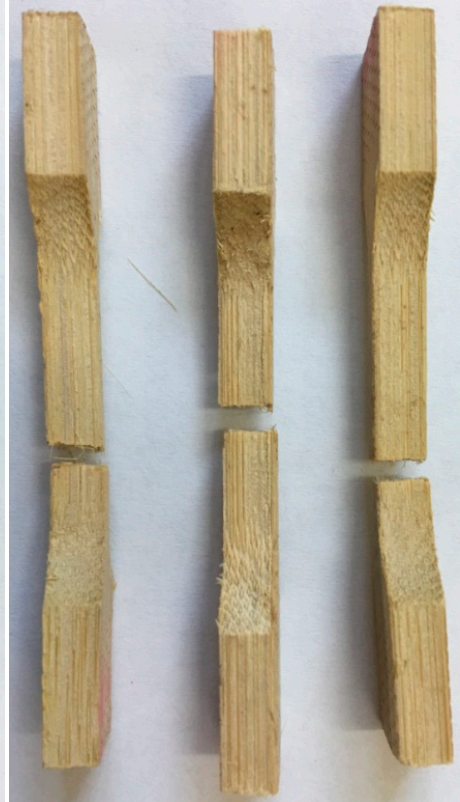

(b)

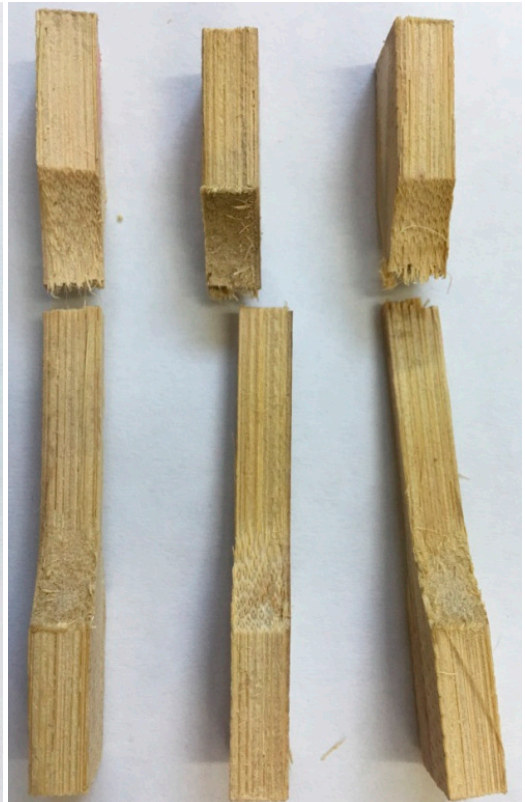

(c)

Figure 10. Tensile fracture of the dog-bone shaped bamboo samples (with moisture content $50 \%$ ) under different loading rate: (a) $2 \mathrm{~mm} / \mathrm{s}$; (b) $20 \mathrm{~mm} / \mathrm{s}$; (c) $200 \mathrm{~mm} / \mathrm{s}$.

The second kind of samples, similar to that in Ref. [47] and machined from the 3 years old bamboo, are dehydrated with ethanol and have 5 samples. The 5 samples are loaded with the tensile loading rate $0.2,2,20,200,500 \mathrm{~mm} / \mathrm{s}$, respectively (Figure 11).

It is well known that bamboo has a kind of functional graded hierarchical structure with the outer layer being stiff and the inner layer being softer [36, 40]. From Figure 11 it is easy to see that the hybrid I-II failure mode is the prominent feature, similar to that given in Ref. [49]. To be specific, they are the mode I tensile failure in the softer inner layer of the tab and the Mode II interfacial shear fracture between the lower fiber density side and the higher fiber density side. In the tensile fracture surface (Figure 11a), the phenomenon of fibers' pull out exists. Also, the loading rates have no influence on the tensile fracture mode.

One thing noteworthy is that for this kind of dog-bone shaped sample, the tensile facture occurs in the tab of the sample, not in the narrow middle part of the sample. This kind of phenomenon indicates that the shape of the dog-bone shaped bamboo samples could affect the tensile fracture mode of the bamboos. 


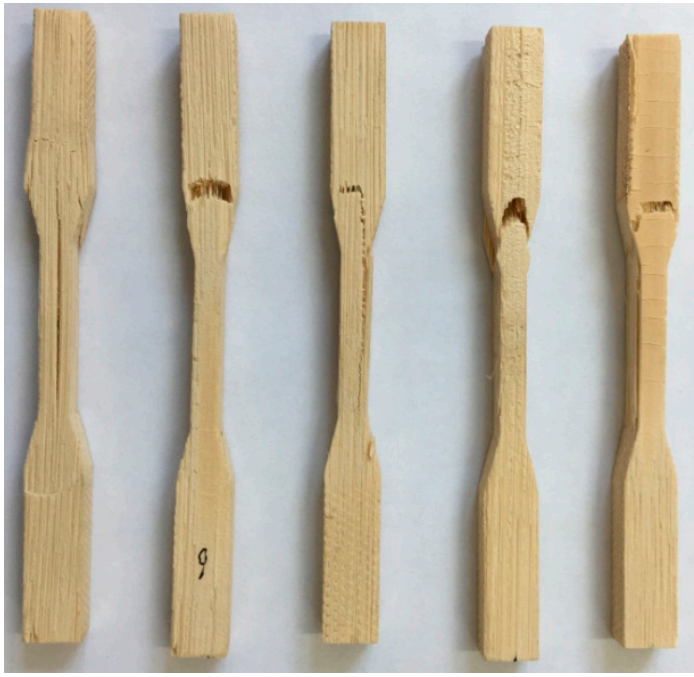

(a)

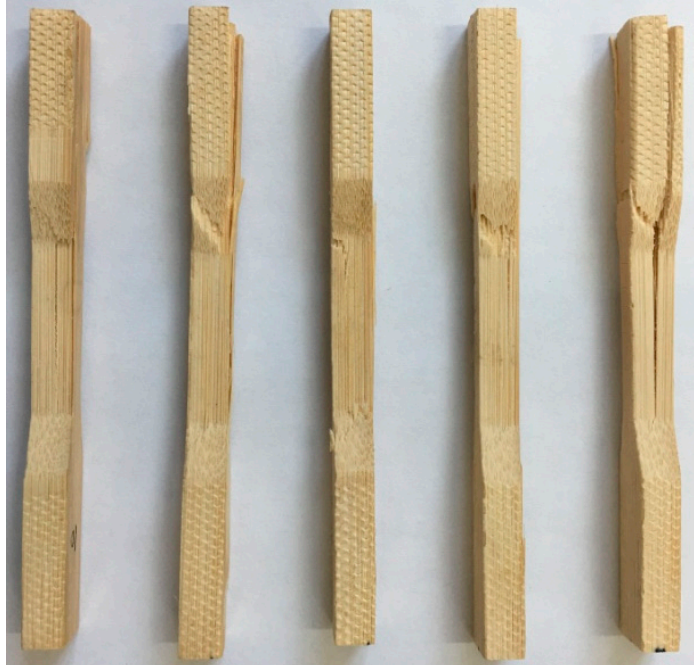

(b)

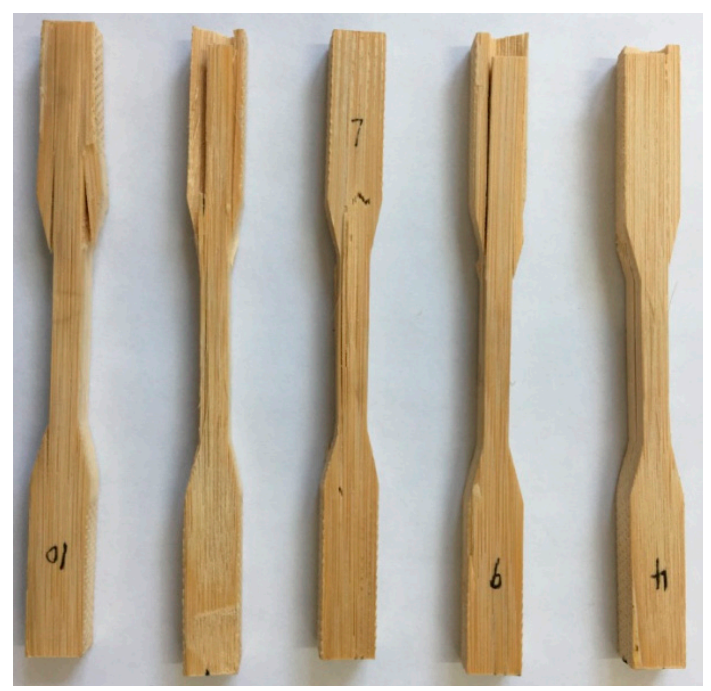

(c)

Figure 11. Tensile fracture of the dog-bone shaped bamboo samples dehydrated with ethanol (from left to right the loading rates are $0.2,2,20,200,500 \mathrm{~mm} / \mathrm{s}$ respectively): (a) front view; (b) side view; (c) back view.

The third kind of samples, machined from the 5 years old Moso bamboo, are soaked in water for more than 24 hours and have 10 samples. The 10 samples are divided into 5 groups and each group contains 2 samples. As shown in Figures 11 and 12 , the 5 groups are loaded with the tensile loading rate $0.2,2,20,200,500 \mathrm{~mm} / \mathrm{s}$, respectively.

From Figure 12, it is easy to see that under different loading rates the fracture modes are different. However, under the same loading rate the fracture modes of the samples are similar. The failure mode of the two samples under loading rate $20 \mathrm{~mm} / \mathrm{s}$ (Figure 12c) is the Mode I brittle fracture and the phenomenon of fibers' pull out exists. The failure modes of the other four groups of samples are not brittle fracture, in which the phenomenon of fiber bridging exists. In short, we could say that different fracture 
modes could appear under different loading rate.

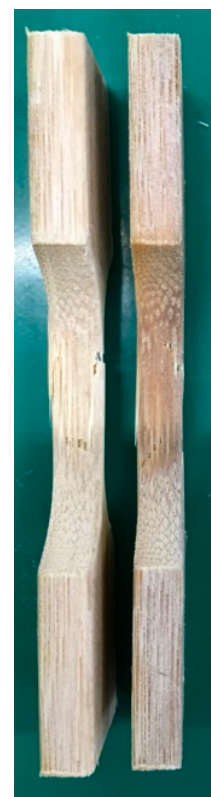

(a)

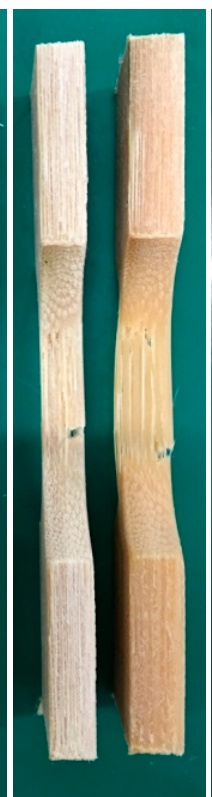

(b)

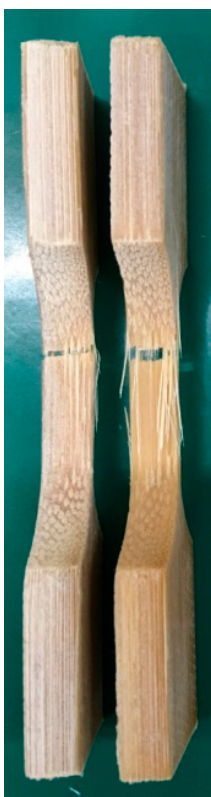

(c)

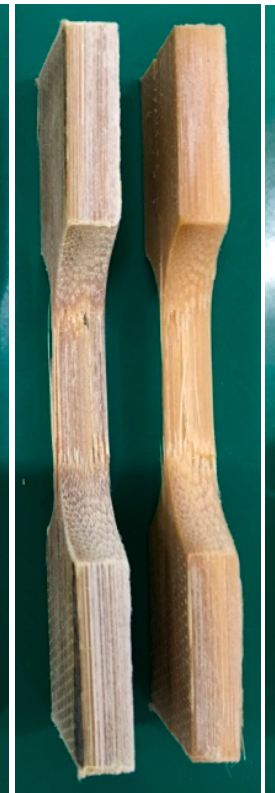

(d)

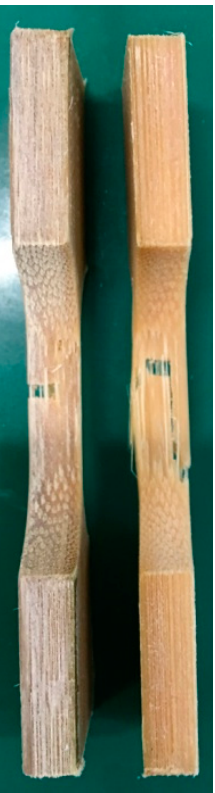

(e)

Figure 12. Tensile fracture (side view) of the dog-bone shaped bamboo samples (soaked in water for more than 24 hours) under different loading rate: (a) $0.2 \mathrm{~mm} / \mathrm{s}$; (b) $2 \mathrm{~mm} / \mathrm{s}$; (c) 20 $\mathrm{mm} / \mathrm{s}$; (d) $200 \mathrm{~mm} / \mathrm{s}$; (e) $500 \mathrm{~mm} / \mathrm{s}$.

Comparing the three kinds of different dog-bone shaped bamboo samples shown in Figures 10-13, we could say that there is no direct relationship between the fracture pattern and moisture content of the bamboos. Also, there is no direct relationship between the fracture pattern and growth age of the bamboos. Besides, the tensile loading rate could affect the fracture pattern of the bamboos in some cases. Also, the shape of the dog-bone shaped bamboo samples might affect the fracture pattern of the bamboos. 


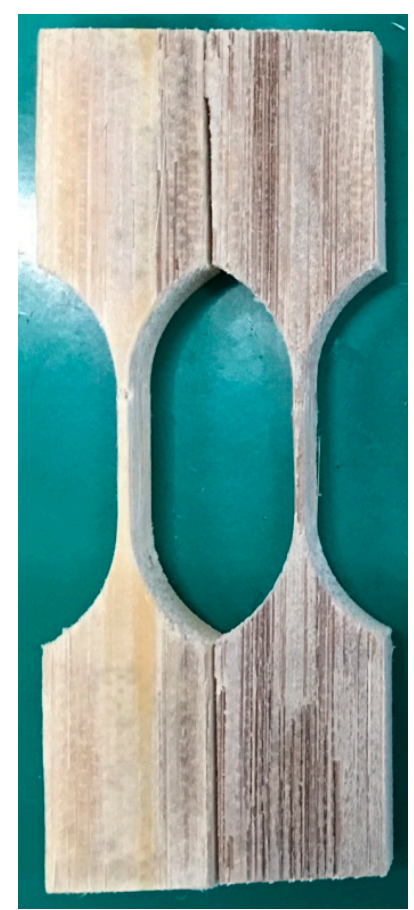

(a)

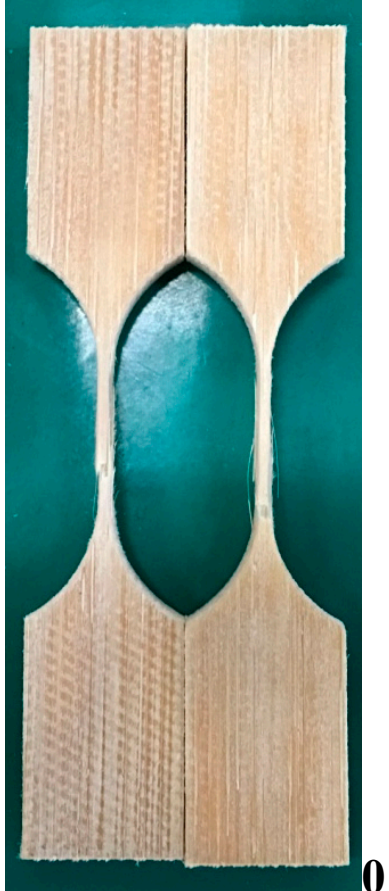

(b)

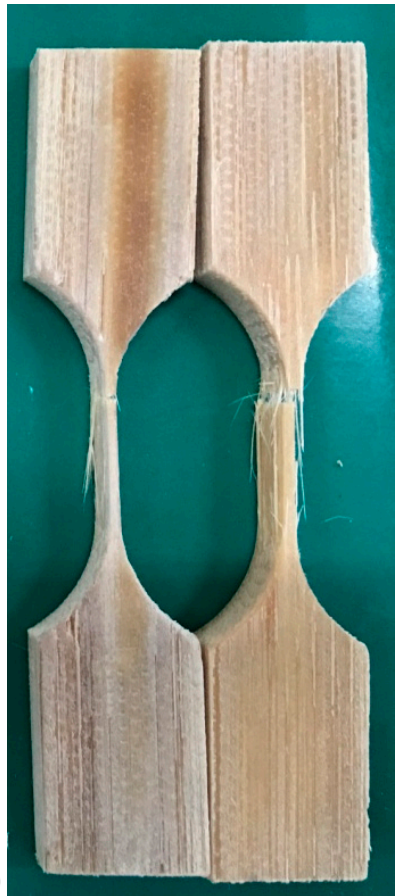

(c)

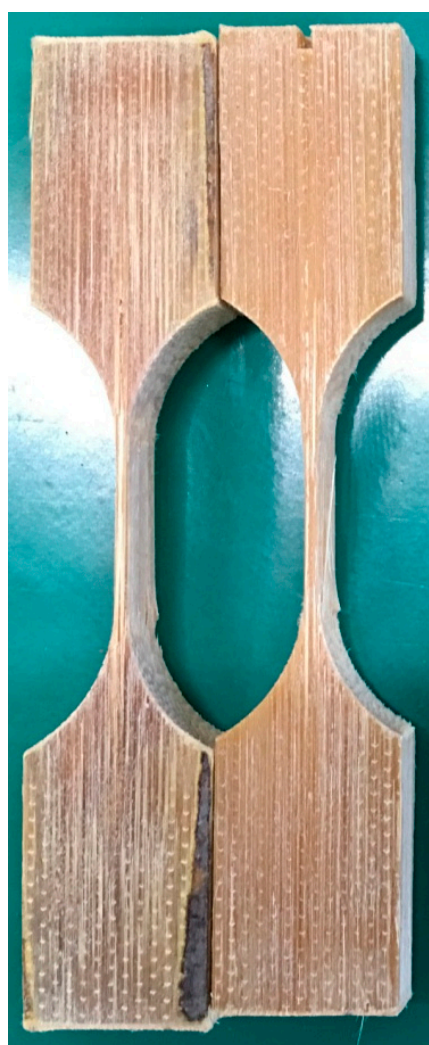

(d)

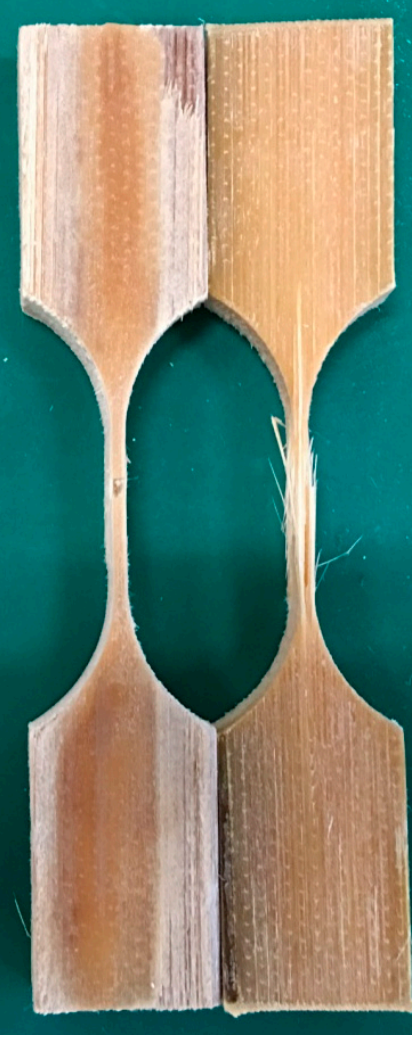

(e)

Figure 13. Tensile fracture (front view) of the dog-bone shaped bamboo samples (soaked in water for more than 24 hours) under different loading rate: (a) $0.2 \mathrm{~mm} / \mathrm{s}$; (b) $2 \mathrm{~mm} / \mathrm{s}$; (c) 20 $\mathrm{mm} / \mathrm{s}$; (d) $200 \mathrm{~mm} / \mathrm{s}$; (e) $500 \mathrm{~mm} / \mathrm{s}$. 


\section{Conclusions}

In this paper, quasi-static and tensile behaviors of the Moso bamboos are experimentally studied. Quasi-static axial compression tests performed on the single nodal Moso bamboo columns show that under the same moisture content, growth age and growing environment, the specific energy absorption (SEA) of the test samples increases with the increase of the out-diameter and thickness of the bamboo columns, indicating that size effect exists for energy absorption of the Moso Bamboos. Quasistatic axial compression tests performed on the multiple bamboo columns demonstrates that there are mainly three failure modes for the constituent single bamboo columns: splitting above the node, splitting below the node and splitting through the node. Tensile tests conducted on three kinds of dog-bone shaped bamboo samples, processed from the longitudinal direction of different Moso bamboos, show that there is no direct relationship between the macroscopic tensile fracture mode and moisture content of the bamboos, as well as the growth age of the bamboos. But in some cases the macroscopic fracture pattern of the bamboos could be affected by the tensile loading rate and the shape of the dog-bone shaped bamboo samples.

\section{Acknowledgements}

The research is supported by the National Natural Science of China under Grant No. 11502162, the NSF of Tianjin under Grant No. 15JCQNJC05100. YS is also supported by the fund (No. SV2015-KF-02) from State Key Laboratory for Strength and Vibration of Mechanical Structures (Xi'an Jiaotong University), the Research Project of State Key Laboratory of Mechanical System and Vibration MSV201611, the Seed Foundation of Tianjin University (No. 2017XRG-0035 and 2017XYF-0009), and the fund (No. GZ1408) from State Key Laboratory of Structural Analysis for Industrial Equipment (Dalian University of Technology).

\section{References}

1. Ghavami, K. Bamboo: Low cost and energy saving construction materials. Modern bamboo structures; Taylor \& Francis Group: London, UK, 2000.

2. Yu, D.; Tan, H.; Ruan, Y. A future bamboo-structure residential building prototype in China: life cycle assessment of energy use and carbon emission. Energ. Build. 2011, 43, 26382646.

3. Nurdiah, E.A. The potential of bamboo as building material in organic shaped buildings. Procedia-Social Behav. Sci. 2016, 216, 30-38.

4. Yu, W.K.; Chung, K.F.; Chan, S.L. Column buckling of structural bamboo. Eng. Struct. 2003, 25, 755-768.

5. Yu, W.K.; Chung, K.F.; Chan, S.L. Axial buckling of bamboo columns in bamboo scaffolds. Eng. Struct. 2005, 27, 61-73. 
6. Xiao, Y.; Zhou, Q.; Shan, B. Design and Construction of Modern Bamboo Bridges. $J$. Bridge Eng. 2010, 15(5), 533-541.

7. Li, H.T.; Zhang, Q.S.; Huang, D.S.; Deeks, A.J. Compressive performance of laminated bamboo. Compos. Part B 2013, 54, 319-328.

8. Li, H.T.; Deeks, A.J., Zhang, Q.S.; Wu, G. Flexural performance of laminated bamboo lumber beams. BioResources, 2016,11(1), 929-943.

9. Li, H.T.; Su, J.W.; Zhang, Q.S.; Deeks, A.J.; Hui, D. Mechanical performance of laminated bamboo column under axial compression. Compos. Part B 2015, 79, 374-382.

10. Li, J.Q.; Yuan, Y.; Guan, X. Assessing the environmental impacts of glued laminated bamboo based on a life cycle assessment. BioResources 2016, 11(1), 1941-1950.

11. Li, Z.; He, M.J.; Tao, D.; Li, M.L. Experimental buckling performance of scrimber composite columns under axial compression. Compos. Part B 2016, 86, 203-213.

12. Li, H.T.; Su, J.W.; Deeks, A.J.; Zhang, Q.S.; Wei, D.D.; Yuan, C.G. Eccentric compression performance of parallel bamboo strand lumber columns. BioResources 2015, 10(4), 70657080 .

13. Chen, G.; Li, H.T.; Zhou, T.; Li, C.L.; Song, Y.Q.; Xu, R. Experimental evaluation on mechanical performance of OSB webbed parallel strand bamboo I-joist with holes in the web. Constr. Build. Mater. 2015, 101, 91-98.

14. Yao, W.; Li, Z.J. Flexural behavior of bamboo-fiber-reinforced mortar laminates. Cement Concr. Res. 2003, 33(1), 15-19.

15. Ghavami, K. Bamboo as reinforcement in structural concrete elements. Cement Concr. Compos. 2005, 27(6), 637-649.

16. Rahman, M.M.; Rashid, M.H.; Hossain, M.A.; Hasan, M.T.; Hasan, M.K. Performance Evaluation of Bamboo Reinforced Concrete Beam. Int. J. Eng. Techn. 2011, 11(04), 142146.

17. Chithambaram, S.J.; Kumar, S. Flexural behaviour of bamboo based ferrocement slab panels with flyash. Constr. Build. Mater. 2017, 134, 641-648.

18. Li, W.T.; Long, Y.L.; Huang, J.; Lin, Y. Axial load behavior of structural bamboo filled with concrete and cement mortar. Constr. Build. Mater. 2017, 148, 273-287.

19. Khatib, A.; Nounu, G. Corrugated bamboo as reinforcement in concrete. Struct. Build. 2017, 170 (4), 311-318.

20. Sudin, R.; Swamy, N. Bamboo and wood fibre cement composites for sustainable infrastructure regeneration. J. Mater. Sci. 2006, 41(21), 6917-6924.

21. Okubo, K.; Fujii, T.; Yamamoto, Y. Development of bamboo-based polymer composites and their mechanical properties. Compos. Part A 2004, 35, 377-383.

22. Sen, T.; Reddy, H.N.J. Application of sisal, bamboo, coir and jute natural composites in structural upgradation. Int. J. Innovat. Manag. Techn. 2011, 2(3), 186-191.

23. Khalil, H.P.S.A.; Bhat, I.U.H.; Jawaid, M.; Zaidon, A.; Hermawan, D.; Hadi, Y.S. Bamboo fiber reinforced biocomposites: A review. Mater. Design 2012, 42, 353-368. 
24. Hojo, T.; Xu, Z.; Yang, Y.; Hamada, H. Tensile properties of bamboo, jute and kenaf matreinforced composite. Energ. Proced. 2014, 56, 72-79.

25. Yu, Y.; Wang, H.; Lu, F; Tian, G; Lin, J. Bamboo fibers for composite applications: a mechanical and morphological investigation. J Mater Sci 2014, 49(6), 2559-2566.

26. Shah, A.U.M.; Sultan, M.T.H.; Jawaid, M.; Cardona, F.; Talib, A.R.A. A Review on the Tensile Properties of Bamboo Fiber Reinforced Polymer Composites. Bioresources 2016, 11(4), 10654-10676.

27. Koizumi, T.; Tsujiuchi, N.; Adachi, A. The Development Of Sound Absorbing Materials Using Natural Bamboo Fibers. High Performance Structures and Composites; Witpress 2002, 59, 158-166.

28. Ghavami, K.; Rodrigues, C.S.; Paciornik, S. Bamboo: functionally graded composite material. Asian J. Civil Eng. (Building and Housing) 2003, 4, 1-10.

29. Ma, J.F.; Chen, W.Y.; Zhao, L.; Zhao, D.H. Elastic Buckling of Bionic Cylindrical Shells Based on Bamboo. J. Bionic Eng. 2008, 5, 231-238.

30. Sun, Y.; Sills, R.B.; Hu, X.; Seh, Z.W.; Xiao, X.; Xu, H.; Luo, W.; Jin, H.; Xin, Y.; Li, T.; Zhang, Z.; Zhou, J.; Cai, W.; Huang, Y.; Cui, Y. A Bamboo-Inspired Nanostructure Design for Flexible, Foldable and Twistable Energy Storage Devices. Nano Lett. 2015, 15, 3899-3906.

31. Inoue, A.; Tochihara, S.; Sato, M.; Shima, H. Universal node distribution in three bamboo species. Trees 2017, 31(4), 1271-1278.

32. Sato, M.; Inoue, A.; Shima, H. Bamboo-inspired optimal design for functionally graded hollow cylinders. PLOS ONE 2017, 12(5), e0175029.

33. Liu, S.; Tong, Z.; Tang Z.; Liu, Y.; Zhang, Z. Bionic design modification of non-convex multi-corner thin-walled columns for improving energy absorption through adding bulkheads. Thin Wall. Struct. 2015, 88, 70-81.

34. Shima, H.; Sato, M.; Inoue, A. Self-adaptive formation of uneven node spacings in wild bamboo. Phys. Rev. E 2016, 93, 022406.

35. Amada, S.; Untao, S. Fracture properties of bamboo. Compos. Part B 2001, 32, 451-459.

36. Tan, T.; Rahbar, N.; Allameh, S.M.; Kwofie, S.; Dissmore, D.; Ghavami, K.; Soboyejo, W.O. Mechanical properties of functionally graded hierarchical bamboo structures. Acta Biomater. 2011, 7, 3796-3803.

37. Li, H.; Shen, S. The mechanical properties of bamboo and vascular bundles. J. Mater. Res. 2011, 26(21), 2749-2756.

38. Shioya, T.; Asahina, T. Mechanical Characteristics of Bamboo. Key Eng. Mater. 2013, 525 $526,609-612$.

39. Yu, Y.; Tian, G.; Wang, H.; Fei, B.; Wang, G. Mechanical characterization of single bamboo fibers with nanoindentation and microtensile technique. Holzforschung 2011, 65, 113-119.

40. Habibia, M.K.; Samaei, A.T.; Gheshlaghi, B.; Lu, J.; Lu, Y. Asymmetric flexural behavior from bamboo's functionally graded hierarchical structure: Underlying mechanisms. Acta 
Biomater. 2015, 16, 178-186.

41. Habibi, M.K.; Tam, L.; Lau, D.; Lu, Y. Viscoelastic damping behavior of structural bamboo material and its microstructural origins. Mechan. Mater. 2016, 97, 184-198.

42. Song, J.; Surjadi, J.U.; Hu, D.; Lu, Y. Fatigue characterization of structural bamboo materials under flexural bending. Int. J. Fatigue 2017, 100, 126-135.

43. Zhang, X.; Li, J.; Yu, Z.; Yu, Y.; Wang, H. Compressive failure mechanism and buckling analysis of the graded hierarchical bamboo structure. J. Mater. Sci. 2017, 52, 6999-7007.

44. Zou, M.; Wei, C.; Li, J.; Xu, S.; Zhang, X. The energy absorption of bamboo under dynamic axial loading. Thin Wall Struct 2015, 95, 255-261.

45. Zou, M.; Xu, S.; Wei, C.; Wang, H.; Liu, Z. A bionic method for the crashworthiness design of thin-walled structures inspired by bamboo. Thin Wall. Struct. 2016, 101, 222-230.

46. Shao, Z; Fang, C; Huang, S; Tian, G. Tensile properties of Moso bamboo (Phyllostachys pubescens) and its components with respect to its fiber-reinforced composite structure. Wood Sci. Technol. 2010, 44, 655-666.

47. Habibi, M.K.; Lu, Y. Crack Propagation in Bamboo's Hierarchical Cellular Structure. Scient. Rep. 2014, 4, 5598 | DOI: 10.1038/srep05598.

48. Chen, H.; Cheng, H.; Wang, G.; Yu, Z.; Shi, S.Q. Tensile properties of bamboo in different sizes. J. Wood Sci. 2015, 61(6), 552-561.

49. Liu, H.; Jiang, Z.; Fei, B.; Hse, C.; Sun, Z. Tensile behaviour and fracture mechanism of moso bamboo. Holzforschung 2015, 69(1), 47-52.

50. Jakovljevic, S.; Lisjak, D.; Alar, Z.; Penava, F. The influence of humidity on mechanical properties of bamboo for bicycles. Constr. Build. Mater. 2017, 150, 35-48. 